This item was submitted to Loughborough's Research Repository by the author.

Items in Figshare are protected by copyright, with all rights reserved, unless otherwise indicated.

\title{
Refiguring digital interventions for energy demand reduction: Designing for life in the digital-material home
}

\section{PLEASE CITE THE PUBLISHED VERSION}

http://www.bloomsbury.com/uk/digital-materialities-9781472592590/

\section{PUBLISHER}

(c) Bloomsbury Publishing

\section{VERSION}

AM (Accepted Manuscript)

\section{PUBLISHER STATEMENT}

This work is made available according to the conditions of the Creative Commons Attribution-NonCommercialNoDerivatives 4.0 International (CC BY-NC-ND 4.0) licence. Full details of this licence are available at: https://creativecommons.org/licenses/by-nc-nd/4.0/

\section{LICENCE}

CC BY-NC-ND 4.0

\section{REPOSITORY RECORD}

Pink, Sarah, Kerstin Leder Mackley, Val Mitchell, Garrath T. Wilson, and T.A. Bhamra. 2019. "Refiguring Digital Interventions for Energy Demand Reduction: Designing for Life in the Digital-material Home". figshare. https://hdl.handle.net/2134/20658. 


\section{CHAPTER 5}

\section{REFIGURING DIGITAL INTERVENTIONS FOR ENERGY DEMAND REDUCTION: DESIGNING FOR LIFE IN THE DIGITAL MATERIAL HOME}

\section{Sarah Pink, Kerstin Leder Mackley, Val Mitchell, Garrath T. Wilson and Tracy Bhamra}

\section{Introduction}

In this chapter, we argue for an approach to design and intervention that builds on the ability of anthropological ethnography to open up new ways of knowing the world, and that attends to digital media as part of this world. Our ethnographic and design research is therefore undertaken in what we understand as a digital-material and sensory environment, and our approach to intervention and change making is informed by this conceptualisation. In what follows, we draw on our experiences of working in an interdisciplinary team - which draws from anthropology, media studies, design and human computer interaction (HCI) research - with the aim of making digital design interventions in everyday home life that will help people reduce their energy demand. We show how the possibility for such an approach has emerged through interdisciplinary working that brings together the dialogue between ethnographic practice and theory with design practice, in ways that both challenge our existing assumptions and that are generative of new possibilities.

Our work is set in an academic, activist and policy context where, for decades now, global climate change and local resource scarcity have led to calls for more 
sustainable energy futures, with digital technologies increasingly expected to provide some, if not the, key solutions for transforming consumption. Within this fastgrowing field, the digital is often appropriated in one of two ways. One scenario sees sensor technologies within ever more interconnected information and communication networks as enabling automated energy-reduction systems that operate 'in the woodwork' (Weiser 1996); the smarter their processing power, the less responsibility lies with the humans who co-inhabit their environments. A second scenario puts agency (and responsibility) back with individuals by finding innovative ways of engaging them through digital services and devices; the aim is to persuade and enable people to actively monitor, control and reduce their energy consumption, in more or less playful or formulaic ways. The first approach renders digital technologies almost invisible, while the second foregrounds, at least in parts, the importance of people's interactions with new material products and digital interfaces.

Social scientists in particular have been critical of both the utopian notion of digital technologies as providing all answers to energy demand reduction questions (cf. Strengers 2013), and of the simplicity of the above human/technological agency dichotomy. While underpinning much engineering and design work in this area, a focus on the latter arguably fails to account for complexities and interrelations, as well as for important socio-cultural, ethical and political implications. As such, scholars have sought alternative ways in which to conceptualise what people do with both energy and digital media. Chapters 3, 5 and 6 of this book (Debora Lanzeni, Mike Michael, and Yolande Strengers' chapters) engage with this context through (differently) critical discussions of the notions of smart cities, smart homes and digital energy feedback technologies and speculative design (if they don’t then we can reference their other works where they do discuss these). By taking specific 
disciplinary approaches and perspectives to this field, these authors highlight the limitations of approaches that depend on either technological or human agency for the success of design initiatives or on interventions that seek to change human behaviour. For instance, Strengers is interested in a sociologically oriented social practice theory approach, which puts the practices of everyday life at the centre of the analysis. Like other social practice theory oriented approaches (e.g. Shove 2010), this reveals the problems associated with the ways in which neo-liberal regimes place responsibility on individuals to change their (energy consumption) behaviour once sensitised to it through behaviour change campaigns. An emphasis on changing individuals’ behaviour, practice theorists argue, clouds the relevance of, and in the process reinforces, other sociotechnical forces and structures. Mike Michael, in contrast, seeks to undermine the idea of the research question that might be successfully answered through conventional sociological processes. His work on energy demand leans towards a more speculative methodology - which is in many ways more akin to the experimental elements of a sensory ethnography approach to doing ethnography and creating research encounters with participants (see Pink 2015). As these discussions show, there are a number of tensions in terms of how to understand energy consumption and create socio-technological ‘solutions’ towards demand reduction. Ultimately, new approaches to both researching with participants and to making everyday life interventions are needed. This, for us, has meant developing ethnographically and theoretically informed ways of engaging with digital media as part of new approaches to design and intervention.

In this chapter, we suggest a reconfiguration of the relationship between theory, research and design intervention that draws on phenomenological anthropology and design research approaches. We explore what happens when the 
apparent dichotomy of digital presence and affordances and human action and improvisation is both disrupted through ethnographic research and utilised by designers. To do this, we reflect on how concepts for digital interventions for energy demand reduction have emerged, between designers and social science researchers, on an interdisciplinary study of domestic energy consumption and digital media use. In doing so, we draw on our research and practice developed on a project that aimed to use digital innovation in energy demand reduction. The LEEDR (Low Effort Energy Demand Reduction (2010- 2014)) project brought together engineers, designers, social anthropologists and computer scientists to explore energy use and digital media engagements in 20 UK family homes. It combined longitudinal energy monitoring with in-depth ethnographic fieldwork and family-oriented design research and practice. For further context, we invite readers to our website Energy and Digital Living where we present and explain our ethnographic findings and design concepts through video clips and writing for a wider audience, at www.energyanddigitalliving.com.

We do not present our project as the perfect 'solution' to the problem of energy demand reduction, or indeed of the question of how to engage with the digital materiality of the home. Because the problem itself is wider and implicates not only the everyday energy consumption activities of individuals in their homes but also a series of other infrastructural and governance issues, it could not be 'solved' through a project such as ours alone. Moreover, the role and significance of digital technologies in this process is yet to be determined (see Strengers, chapter 4 this volume). Rather our work is part of a journey towards developing new ways of working between ethnographers and designers, within and in relation to a digitalmaterial environment and, in the case of this particular project, towards energy 
demand reduction. It is in that sense a speculative process, in that we did not know what would emerge from our research relationship when we began. In the spirit of the speculative design processes that are described by Mike Michael and Bill Gaver (see Michael, chapter 6, this volume), as our project came to a conclusion we found ourselves in a position to show what we have learned from this process and to reflect on how it would enable us to craft future design ethnography relationships in new and generative relationships. Understanding the nature and significance of digital-material dimensions can be considered both a research and design challenge. It is also this inspiration that we invite readers to take with them as the field of intervention in a digital-material world evolves further and through new projects.

\section{Researching through digital materiality: project and methods}

To be able to understand how and where to make digital design interventions towards everyday sustainability our project aimed to reframe the approaches to energy demand reduction that are driven by the technological, engineering, behavioural and social practice theory agendas we have highlighted above. Instead we sought to refigure what people do with digital media in their everyday lives in their homes, how digital technologies already form part of everyday life, in both their tangible and intangible forms, and how people improvise with digital technologies in everyday life. In doing so, we appreciate the potential of ordinary people as everyday designers who have a certain form of agency, which emerges through their relationships with digital technologies.

We also create something of a false separation between the environment of and activity in the home, in order to distinguish these for the purposes of understanding the ways that both are implicated in design processes. At the end of the 
section we bring these together to suggest that their mutuality needs to inform the way we understand the home and the ways that interventions might be produced in it. First, we briefly explain the research methods we used, and the research design that informed the ways in which we developed our ethnographic encounters.

Our research design set out to understand how the home was made, experienced and maintained (and the role of digital media in this), and how a set of specific everyday activities, which had been identified as potentially high energy consuming, including laundry, media use, showering/bathing, and use of heating, were actually accomplished. We were also concerned with the contingencies and human improvisations that these activities and environments are shaped by. Our ethnography thus had an emphasis on the experience of home, and how the unspoken, mundane, often invisible and otherwise unknown about elements of everyday routines and lives underpinned the ways in which energy is consumed. To achieve this, our ethnographic research followed a three-stage process. The video tour was designed to understand the 'sensory aesthetic' of home, how it was made, maintained and experienced (Pink and Leder Mackley 2012). The tours pulled in the things, feelings (sensory and affective) and activities through which the home was constituted as our participants led us on a route through it. They enabled us to learn about how the home was known and sensed, where and how activities were distributed throughout it temporally and spatially. As part of the video tour encounter we also invited our participants to demonstrate to us, through re-enactments, how they went about their everyday routines of getting up and going out in the morning and going to bed at night. The re-enactment studies enabled us to gain an understanding of the ways in which everyday routines were accomplished, the idiosyncrasies and improvisation that they entailed, and the sensory tacit ways of knowing and moving through the 
home that were part of the often never spoken about ways in which people consume energy as they make their homes and selves 'feel right' at these pivotal moments of the day (Pink and Leder Mackley 2014). We gave copies of all our video materials to participants and invited them to comment on and ask for edits in them, as part of both our research and ethics process. We also as the next stage of our research worked with a smaller sample of 11 households with whom we focused on exploring how they performed a series of everyday activities. These studies of everyday activities enabled us to understand better how the tasks of doing the laundry, showering, using media and other activities are interwoven with each other and with the materiality, sensoriality, affect and atmospheres of home. Our research taught us that these cannot easily be separated out as distinct practices that might be redesigned but, rather, and as we show below, we might need to think of other categories that might be identified through ethnography in order to find ways through which to design for energy demand reduction. This, then, became a matter of reframing what it is that we think we are designing for.

\section{The digital material environment of home: presence, co-presence and}

\section{atmosphere}

Our approach to analysing our ethnographic findings was developed through a series of theoretical-ethnographic dialogues which are discussed in more depth elsewhere in the articles we refer to below (see also Leder Mackley and Pink 2013), and which have contributed to debates in media studies, sociology and human geography. Here we summarise these contributions to outline how we developed a focus on the concepts of presence/co-presence and atmospheres, which eventually played a role in the production of the insights the ethnography team offered to the design team. The 
purpose of the discussion here is also to present this as a framework for considering how we might understand the environments, actions and atmospheres of homes as sites of possibility for digital design interventions.

Our sensory video ethnographies of home set out to develop a new understanding of energy demand in the home. Our study focused on how and why energy was consumed in the homes of our participants, along with a special or dual focus on the place of media in this process. We were not only interested in how digital media consumed energy, but also in the ways in which they were integral to the mundane lives of our participants, given that our objective was to also produce insights into how and where digital design interventions for energy demand reduction might be introduced. Our approach to the home was informed and underpinned by existing research into the sensory, material and mediated qualities and affordances of home. These three themes offered us a rich ethnographic and theoretical background to build on, and we used existing theoretical ideas in dialogue with our own ethnographic findings. Our ethnographic research drew on the existing tradition of material culture studies of home, as developed by Danny Miller (eg 1988, 2001), the notion of the sensory home developed by Sarah Pink (2004) and the tradition of nonmedia-centric media studies, specifically relating to home as developed by David Morley (eg 2000) and followed through in the more phenomenological work of Shaun Moores (eg 2012) and Nick Couldry and Tim Markham (eg 2008). These existing works offered us a way of understanding the home that was 1) constituted by its materiality in relation to human actors, 2) a sensory and affective domain filled with things and activities that were not necessarily tangible or ever spoken about but sensed and tacitly known, and 3) a mediated site, where media was part of both of the 
materiality of home and embedded and often appropriated into the routines of human activity and feeling that were co-constitutive of home.

Our work built on this existing understanding of home in two ways that we recount here briefly and to which here we also add an additional layer of analysis by accounting more explicitly for the proposal that digital media are part of the atmosphere of home. As such we define the digital materiality of home in terms of its qualities not only as a material and sensory/affective environment, but as being constituted as an atmosphere (Pink and Leder Mackley 2015). This, we argue, offers a way of bringing together and reframing the materiality, sensoriality and mediatedness of home. It means that we are designing therefore not simply into a material, technological or sensory home but into an atmosphere generated through people's embodied relations with a digital-material-sensory environment. This atmosphere will influence how any interventions are experienced and engaged with, and will itself be impacted by interventions. It is therefore also the atmospheres of home that we suggest need to be accounted for when designing for/with homes. Our existing publications have brought to the fore three key points that have formed the basis for this thinking.

First, through an analysis of how participants in our research understood their digital media technologies in relation to the ambiguous states and statuses of on, off and standby modes, we developed the notion of media as 'presence' (Pink and Leder Mackley 2013). In the non-media-centric media studies work we have cited above, media still tend to be understood specifically in relation to their uses for their content and for communications. Our ethnography showed us how digital media were used in the home in a series of ways beyond their value for content or communication. We learned how people put media on at bedtime to help them go to sleep, unbothered by 
the programme that was on. We also learned how people's perceptions of the different states of on/off-ness of media was part of the way they sensed their homes, knowing that the home 'felt right' if and when media were switched to the 'right' status. This was often achieved through bed time routines where, depending on the contingencies of the material and social arrangements of home, media would be put on, off or on a timer to go onto standby mode (Pink and Leder Mackley 2013). The other type of media 'on-ness' can be described through the notion of digital co-presence, whereby through mobile and locative media people are often continually on-line with the potential to access and 'be with', or with an affective sense of the presence of others who are in different and possibly distant physical locations (see Pink et al 2015 for a discussion of digital relationships). In terms of energy demand, as discussed in more detail elsewhere (Pink forthcoming), standby mode can be a relatively high consumer of electricity, and therefore something that would have potential for reduction. Yet it is also a mode of being, of material, sensory and social presence in the home for which we need to account through design.

Second, there has recently been a (re)turn of interest to the concept of atmosphere (e.g. Bohme, 1993), particularly in the work of scholars in human geography (Anderson 2009, Bissell 2011, Edensor 2012, 2014), as well as in anthropology (eg Bille et al 2015). In this literature atmosphere is not seen as something separate from people or environments, but as embodied and affective, emerging from bodies rather than enveloping them from elsewhere. We, drawing on the work of Ingold, have gone on to further theorise atmospheres as something that is also emergent from what Ingold calls 'making' - that is from the everyday forms of improvisory activity that people engage in during their everyday lives. Therefore we have argued that 'we can understand the atmospheres as emergent from processes of 
making. That is from the encounters between people, materials and other elements of the environments of which they are part (eg air, light, warmth, scents). Atmospheres are not as such products but they are produced or emergent ongoingly as people improvise their ways through the world.' (Pink and Leder Mackley 2015). We found, when we looked at the ethnographic detail, that our participants could be understood, as everyday makers of atmospheres in their home, in precisely this way. For instance as they walked through their homes at bed time, switching on and off the lights, closing curtains, plugging in things to charge and setting up technologies to 'work' while they were asleep - as such making the material configuration and atmosphere of the bed time home as they moved through (Pink and Leder Mackley 2015).

Bringing this argument together with that outlined above - where we have argued that media presence is also part of the home - invites us to take this further. This has meant generating a definition of the digital materiality of home, which takes the atmosphere of home to be something that goes beyond the relationship between materiality and the embodied/affective (as advanced in the human geography literature cited above), and which instead also encompasses the affordances and qualities of digital technologies - that is the digital presence and co-presence that is generated by media in ways that go beyond (but of course also includes) their functions for content and communication. The implication of this is that to design for change in the home we need to account for these ways in which media feel and participate in the generation of atmospheres of home, both through their technological presence and through the sociality of digital co-presence of being online with others.

The third element of this relates to the ways in which improvisory human activity is part of this process, as outlined in the next section. 


\section{Human activity in the home: flows, movement and making}

As we have shown in the last section, for us the digital and material are inseparable elements of the environment of home, they become interwoven in its atmosphere. Energy demand, as we have already indicated above, is also part of the way in which the atmospheres of home are constituted. Within this broad way of understanding the home, however, we also need to understand what people are doing as they go about their normal everyday energy consuming activities. Conventional psychological studies of how people consume energy tend to focus on human 'behaviour' (e.g. Abrahamse et al. 2007, Steg and Vlek 2009) while it is quite standard in sociology to use a unit of 'social practices' to study and divide up the activities through which people consume energy (e.g. Shove 2010, and see Strengers, this volume). Anthropologists have always been interested in what people do, and have used a range of concepts through which to understand this. Here we draw on the particular branch of phenomenological anthropology that is also closely associated with (and underpins much of) the emergent subdiscipline of Design Anthropology (refs). In this field ideas that emphasise the ongoingness of improvisation, as part of everyday life, and in particular the work of Ingold (2012) in phenomenological anthropology, have been engaged to inform new approaches to co-design that bring together anthropological ethnography and design research (Gunn and Donnovan, 2012; Otto and Smith, 2013; Pink et al., 2013, Akama and Prendiville 2013).

As discussed elsewhere (Pink and Leder Mackley 2015), by bringing together a focus on the atmospheres of home with the ideas of improvisation and agency, and the focus on movement developed in the work of Ingold (eg 2000, 2010), we can begin to understand the question of where and how to design into everyday life in the home in new ways. Our focus in this chapter is more practical and concerned 
specifically with the ways in which we have brought together ethnography and design practice and ways of knowing, therefore we do not go into detail concerning the theoretical developments that this implies (see Pink and Leder Mackley 2015 for a detailed account). However, to preface the connection between our ethnographic work and digital design interventions discussed below, we outline how the concepts of movement and improvisation connect to that of atmosphere.

The theoretical work that informs the way in which we understand the purpose and affordances of the digital design interventions discussion involves two sets of concepts. Although these might not be in any objective way different types of concepts, here we are engaging them for different purposes. In the last section we wrote about concepts of atmosphere and presence. These are not static states at all, but on-goingly made and part of the dynamic nature of the home as a site for research and investigation. However, for our purposes here we are identifying these as in some way distinct, in that they are concepts that we are using to define the environment of home. In this section, we focus on a set of concepts that we wish to use in relation to those of atmosphere and presence, which we see as action concepts and which, conceptualised as such, help us to translate them through into the design process. We use these to refer to three forms of action making/improvisation, movement and flow. However, we would emphasise the action is of course not only human, but rather in part the action (movement and flow) is also of the atmosphere. Thus rendering people, things and intangibles all part of the same moving and changing environment and meaning that action and atmosphere are co-constituting of each other.

The above point stated, because we want to design for and with people - that is with the participants in our projects - it is however necessary to address the question of where and how people are active in this theoretical framework. Questions 
concerning human agency and intentionality, where these are situated, and from where they are derived are complex and difficult to resolve theoretically or empirically. For the purposes of our argument here, Ingold's point which has held currency in design anthropology is useful, particularly because it enables us to focus on the concept of improvisation as a way in which to engage with both the question of what people do as they go about their everyday lives, more broadly, and with how they might engage with digital design interventions that are made precisely to become part of their everyday improvisory activities and also part of the ways in which they 'feel' the affective atmospheres of home. As Pink and Leder Mackley emphasise elsewhere, Elizabeth Hallam and Tim Ingold see improvisation as ‘as a necessary condition because there is no existing template that instructs us in how to deal with the continually changing contingencies of life' (Hallam and Ingold, 2007: 2). They ‘theorise improvisation further as "generative”, “relational”, “temporal”, “inseparable from our performative engagements with the materials that surround us” (2007: 3)' and 'Ingold proposes that designing is a way of imagining the future that is openended: “about hopes and dreams rather than plans and predictions” (2012: 29)' (Pink and Leder Mackley forthcoming). When we put our participants at the centre of the analysis we also came to conceptualise our participants as 'directors of flow' in the home. For example, we observed how they would continually be working with, initiating or curtailing flows of warm or cold air, smells, sounds, lighting and more as they navigated these intangible yet mobile affordances of homes through open window, radiators, cooking, extractor fans and more (Pink and Leder Mackley 2014). Such work requires engaging with the contingencies of the home as a site of ongoing change - socially, materially and in terms of its intangible and digital elements. It is 
also work that requires improvisation, which might be on-the-spot or might be part of an ongoing process of changing routines over time through forms of adjustment.

We argue that in order to design digital interventions for everyday change, then, we need to precisely engage with this kind of everyday human activity - that is the improvisory potential of our research participants - as the route through which to move towards sustainable digital energy futures. In the context of the project discussed here, the digital, material, atmospheric qualities and affordances of home, discussed in the previous section, therefore can be conceptualised as constituting sites for digital design interventions. They are inhabited not just by improvisory active people, sensing feeling bodies, but also by the presence of digital technologies, flows of air, sound and light. They are also, crucially, sites of uncertainty, which people however know enough about and can hope enough for, when they make changes in them, to be able to routinely navigate and accomplish mundane routines that are generative of the very homes they are part of.

\section{From research findings to connecting with design}

The work that we report on in the previous section focuses on the findings of the ethnographic-theoretical dialogue through which we were able to develop broad understandings of what our participants were doing in their home. In this section we discuss examples of three of the key insights for design that emerged from this: feeling right; ongoing improvisation; and people as directors of flows. Then in the following section we turn to the design process and to the implications of these findings for the introduction of digital design interventions.

The concept of feeling right was at the core of our ethnographic research, in that as explained above, our initial question to participants related to how they made 
(or sought to make) their homes feel right. As our ethnographic work developed, we learned how making the home feel right involved a range of different materials, intangible elements and activities which would maintain this feeling. We also learned how participants developed sensations of uneasiness or disquiet when they knew that everyday routines related to energy and technology use were not accomplished. For example, as we describe elsewhere (Pink and Leder Mackley 2013), Alan, one participant, told us how his daughter felt uneasy if all of the electricity sources were not switched off at bed time, and another participant described a situation where he would have all his young children in the car ready to leave for school and then realise that the oldest son had not switched off his Xbox, but that it was now too late to go back to do so. These ways of making the home feel right, or not, can be theorised in relation to the notion of affective atmospheres of home discussed in the previous section.

The idea of ongoing improvisation towards making the home feel right also emerged from our ethnographic work. For example, when our participants discussed their night time routines with us, we learned about how Alan, mentioned above, had developed ways in which to ensure that switching off at bed time was easy, through the use of a wooden stick to reach switches, and an extension lead in one bed room. Another participant, Lee, showed us how he used his mobile phone as a light, and one of his lights as a memory device (cf. Pink and Leder Mackley 2014). These activities were subsequently understood theoretically as part of the process of ongoing everyday improvisation and creativity discussed in the previous section, and also contributing to the making of affective atmospheres of home

The notion of people as directors of flows who are ongoingly working with and navigating the contingencies of everyday lives emerged from our work with 
participants that showed us they were continually dealing with the sounds of music or TV, smells, flows of warmth or draughts of cold air and other, often invisible, elements that flow through the home. For instance, Barbara described how she controlled flows of heating, cooking smells, music and lighting in the kitchen so she could communicate with her husband who had a hearing impairment (cf. Pink and Leder Mackley 2015). Rhodes described to us how she would control the flows of sound from the washing machine and boiler, create a particular sensory environment in her son's bedroom and deal with the draughts in the colder parts of her house (cf. Pink and Leder Mackley 2012). These examples and others showed us how our participants were continually working with these different flows and contingencies in relation to each other, again to make the home feel right, and as such as part of the making of the affective atmosphere of home.

\section{Re-figuring the design process}

In this section, we turn to the design process to explain how the approach we take both builds on and departs from existing practice within user-centred design and HCI. We then outline how the reconceptualization of the digital-material and experiential environment of home outlined in the previous section impacts on the ways in which we explore and re-frame the design space and our approach to intervention design. In the third part of the discussion our focus then moves on to opening up the design space through a deeper engagement with sensory-ethnographic concepts and research materials. Here we outline how three of the key concepts that emerged from the design-ethnography approach outlined above are used to re-think the world for which we were designing and how and where digital interventions might participate in this world. 
Elsewhere (Pink et al 2013) we have described the theoretical similarities between the sensory ethnography approach and the notion of embodied interaction (Dourish 2001). Core to both is the notion that the meaning of the world, in this case the home, is revealed through our encounters with it; how we react to it, move through it and engage with it to meet our needs and contingency plan. The sensory ethnography approach has provided the design team with the opportunity to re-frame their consideration of the 'domestic energy problem' and to foreground consideration of how people create their desired experience of home. Previous research [Strengers etc.] has shown that providing householders with feedback on their energy use has limited success and, therefore, the design team prioritised consideration of how our interventions could be embedded into everyday life. The sensory ethnography research has encouraged us to reframe our thinking, to systemically consider how the different everyday routines which make the home and self 'feel right', and the energy consumed as part of these activities, are in real life interwoven and inseparable, culminating in the creation of tacit bespoke atmospheres in which our interventions will become part of the digital materiality of the home.

Defining, framing and iteratively re-framing the problem space is a core component of the creative design process and is part of the evolving collaboration between the design and social teams. We have worked closely together to find innovative approaches and methods for bringing the new ways of knowing emerging from the sensory ethnography into our ideation processes. Bridging from ethnography into design can be problematic: the rich and complex representations of reality emerging from ethnographic encounters can conflict with the designer's desire to structure the messiness of everyday life in order to bound (at least temporarily) the problem space and begin generating solutions. We have sought to overcome this by 
using the ethnographic materials to provide different entry points for design, in other words to look for alternative ways to frame the problem space that lead us away from providing direct feedback on energy use. Key to this approach has been to generate forward-facing opportunity statements as an interdisciplinary team.

Opportunity statements re-frame identified insights, moving from an understanding of the observed, re-enacted and reflected upon towards the creation of speculative 'How Might We' statements. For example, from the ethnography it was apparent that households with hot water tanks in their homes treated hot water as a limited, tangible resource, the use of which is negotiated between family members using tacit knowledge of different family members' hygiene routines. For households with a combi-boiler where hot water is heated on demand, water had become like electricity; an apparently infinite resource. Longer and more frequent showering was seen within these households and consequentially higher energy use. This insight was re-framed as the opportunity statement: 'How might we encourage householders to consider energy as a finite material resource?'. The design response to this was the digital intervention concept 'Finite'. Finite evolved from an initial idea of creating a digital well to tangibly represent energy use (gas, electricity and water). The 'well' gradually drains in line with resource consumption targets set by the householders visually prompting the householder to consider 'how much do I have left?' rather than trying to make meaning of the often intangible answer to the question 'how much have I consumed?’; a continually cited issue with digital energy feedback technologies. The app, therefore, attempts to use digital media to evoke the materiality of the absent water tank whilst extending this metaphor to gas and electricity use. When we take the developing of this design concept back to the theoretical work that has informed the ethnographic analysis, we might also posit an 
explanation that supports this intervention: by evoking the materiality of the water as stored in a tank we might also evoke the sensation, the feeling that water is finite as a resource, that is the embodied sensation that the water supply is limited and a way of anticipating its end that is not simply cognitive. Returning to the discussion of the affective atmosphere of home, therefore, the continuing question which could be explored through the use of the app would be to ask how this this relationship between the digital intervention, the making digitally tangible of the materiality of water and embodied feelings about water use have emerged. This feeds into a wider question about how we might design interventions that enable new ways in which sustainable uses of water can encouraged precisely because they 'feel right'

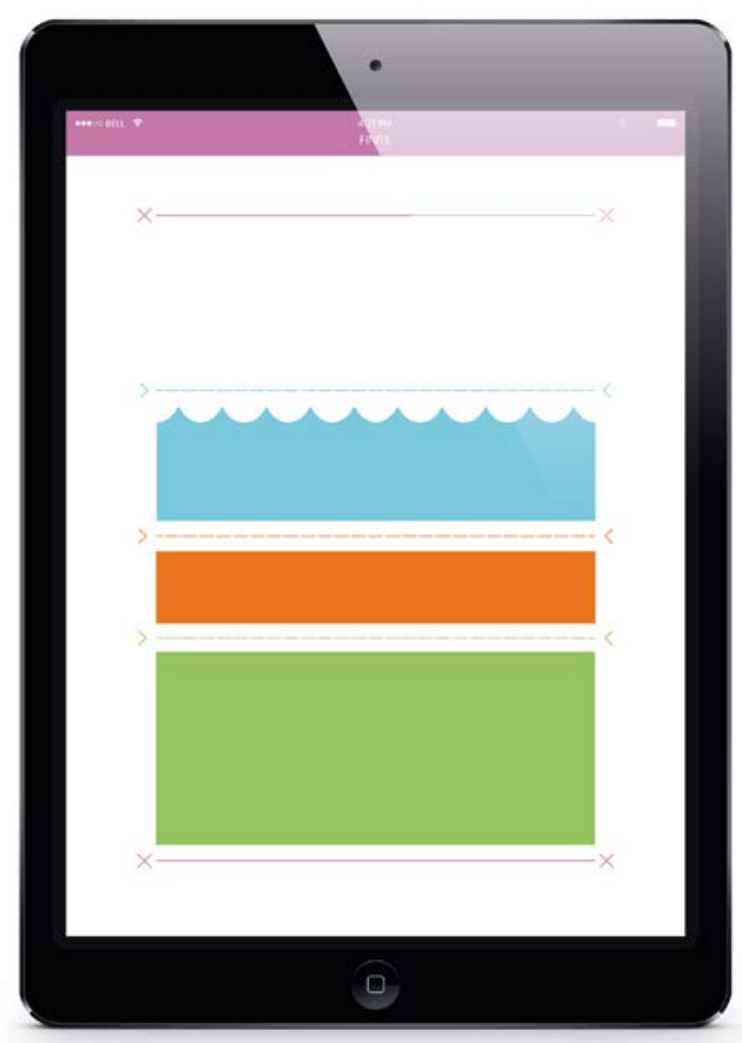

Figure 5.1. Finite - the digital well. Copyright LEEDR. 
A further response to the sensory ethnography is the digital intervention concept 'Anima', an app that focusses on the insights that emerged from ethnographic knowledge on how households manage routines and improvise on an ongoing basis to make the home 'feel right'. In response, the design team were led to speculate whether a digital concept could be designed to encourage households to consider and respond to the well-being of the home in a similar manner to the way that they themselves respond to the mood and well-being of other family members, again attempting to use the digital to create a tangible perception of materiality. Responding to 'How Might We' statements concerning the dynamics of multi-generational households, family values, and perceptions of time, Anima is a proxy for the heartbeat of the home, a dynamic illustration of the home's energy use and activity levels that adapts in relation to predefined targets (set by the householders). As energy consumption or activity levels rise above their respective targets, Anima will give the illusion of stress; moving from a calm and regular pulse to an exaggerated, irregular and frenetic pulse. The householder is encouraged to explore, not through (dis)engagement with complex statistical representation, but by pulling, twisting and bouncing the Anima for an active exploration of the invisible consequences of their actions and routines - a critical departure from existing passive feedback 'solutions'. The questions that follow from the possibilities offered by Amima, as for Finite, take us back to the ethnographic analysis. Here Anima connects to the ongoing ways in which our participants were improvising in and modifying their everyday routines and activities, as well as with the ways in which they imagined the longer term evolution of the materiality of their homes over time. The questions this raises is how Anima will enable its users to engage with these embodied ways of feeling the home, its 
temporality and its stress as participants seek to make the home 'feel right' via Anima.

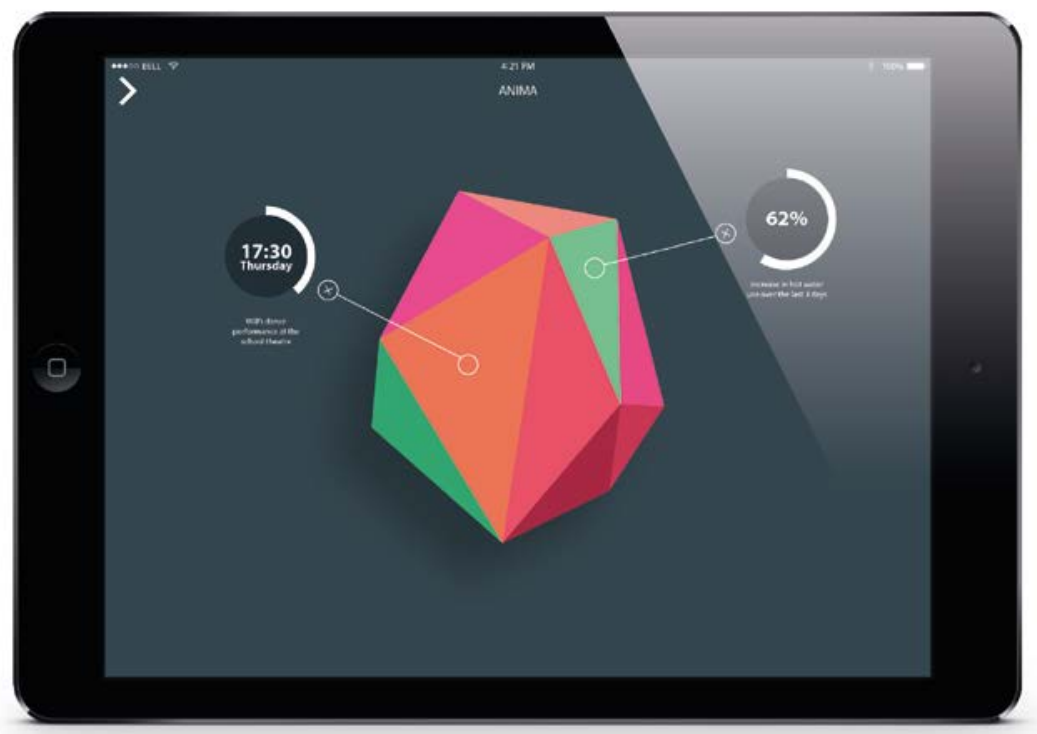

Figure 5.2. Anima - home is where the heart is. Copyright LEEDR.

Finally, we show how this wider framework shifts emphasis away from what designers increasingly criticise as localised and short-sighted intervention processes to a more integrated approach to media innovation that considers human-technological agency as fluid, multi-sited and contingent.

As the home is increasingly becoming a site of complex systems within systems, permeated by both technocratic and people-led interplay of the networked digital and material, people's perception and the affordances of interrelations is critical to facilitating them as everyday improvisors and directors of flow. Embracing this sensory ethnographic insight, Kairos is a digital intervention concept that allows inhabitants to create ad-hoc intelligent profiles for their energy consuming appliances 
that are both grounded and situated within their daily lives; potentially solving the problematic dichotomy between human and technological agency. Representing time qualitatively, abandoning traditional approaches to time and activity management, activities can be selected to build unique Kairos profiles, as an individual or as a family, with 'user'-created digital flows (using IF/THEN conditional statements) to make new interrelations of activity. For example, the flow of sound by objects (i.e. the sound of the washing machine drum spinning) within the laundry process was identified as a constraint on when laundry activities could be performed - the atmosphere was perceived as unconfigurable and so avoidance measures were implemented. Kairos allows the user to connect a baby's cot (monitored via an inbuilt accelerometer) to the washing machine. Using the conditional statement 'IF the baby is in light sleep, THEN reduce the washers spin speed', the new interrelation enables both improvisation (by the user) and optimisation (by the technology). Energy is still consumed, but the material and sensory improvisory tendencies of inhabitants are empowered through the design of the digital, enabling the potential for energy reduction. As such we can interpret Kairos as a technology that will be able to participate in the making of the affective atmospheres of home, in ways that build on inhabitants' existing ways of making their homes 'feel right' in relation to multiple contingencies of everyday life. Kairos in particular connects with our ethnographic insight that people become 'directors of flows' in their own homes, as they improvise in everyday life to make the home feel right. Kairos both acknowledges and has the potential to become a participant in this process, in ways that specifically orient users towards energy demand reduction. 


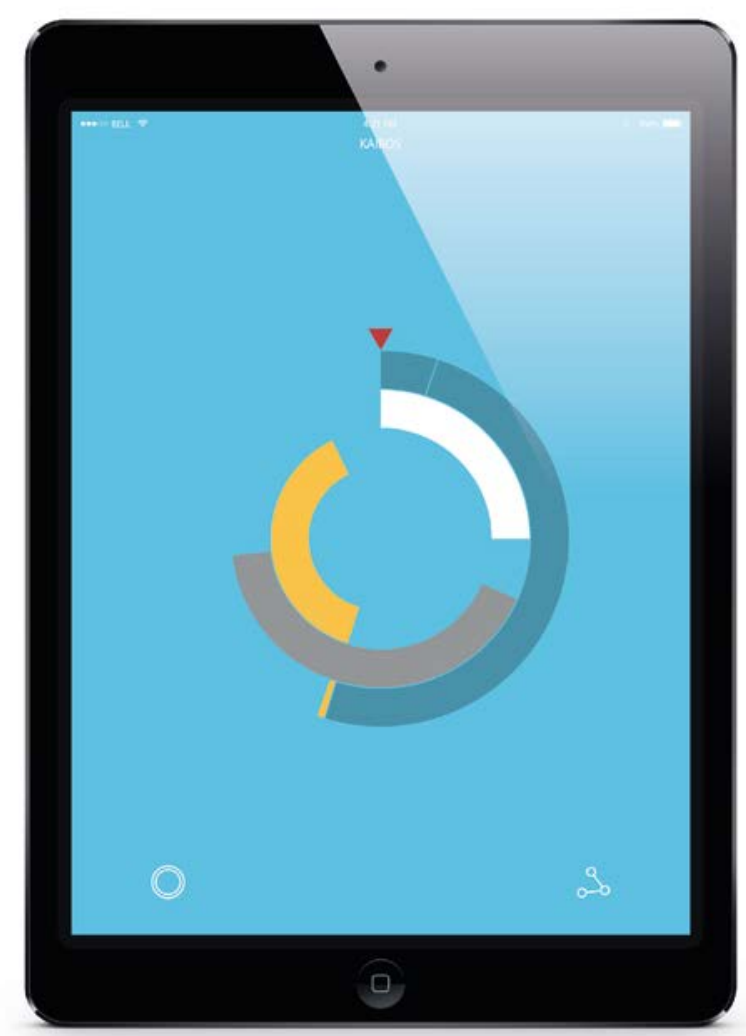

Figure 5.3. Kairos - creating the opportune moment. Copyright LEEDR.

\section{Conclusion}

In this chapter, we have drawn together a series of stages and elements of a four-year research project which involved ethnographers and designers learning how to work together, share practices, research materials, ideas and thinking, towards developing digital interventions for energy demand reduction. Just as the analytical trails between the sections of this chapter are not perfect, neither were the connections that run through our collaboration. There are gaps and there are leaps of faith that made these gaps close up. Some of the connections between the digital interventions that have been developed and the research findings did not become apparent until viewed in 
retrospect. Again here the connections are not seamless or sure of themselves, but rather, as in the case of the concluding sentence to our presentation of Kairos, they are about the potentiality of these technologies to participate with users in the making of lower energy demand futures.

In the introduction to this chapter, we made reference to critical discourses surrounding the role of digital media in the process of energy demand reduction. Although design concepts for digital interventions constitute key outcomes of our project, we have not been disconnected from these debates but have actively engaged with them through our interdisciplinary collaboration and, particularly, by employing a sensory ethnographic framework that offered new routes towards understanding problems and solutions. As the resultant design concepts exemplify, we have found that explorations of digital-material relations can be instructive as research and (speculative) design challenges in their own right; digital media, with their affordances as both materially and immaterially present - as part and co-constitutive of the home, of its atmosphere and its inhabitants' activities - have lent themselves to the study of energy which itself lacks tangibility but is still, in a variety of ways, linked to material infrastructures. Both can be understood and interrogated through a theoretical framework that attends to the ways in which the home is experienced, known, made and imagined through sensory-embodied sensations and doings.

To conclude, we would re-iterate that the relationship between ethnographic practice and digital design is emergent; a work in progress, and itself a speculative project. Our own project can be seen as both a work in making a set of prototypes that we wish to be successful in their task of enabling energy demand reduction amongst their users. Yet at the same time we suggest that an equally important outcome of our work concerns what we have been able to learn about how digital technologies, 
design and human everyday activities and environments of home might come together. This knowledge, we propose, offers a strong basis not only for design in the particular context in which we have worked, but also as a starting point for research design for future work.

\section{References}

Abrahamse, W., L. Steg, C. Vlek and T. Rothengatter (2007) 'The effect of tailored information, goal setting, and tailored feedback on household energy use, energy-related behaviors, and behavioural antecedents’ Journal of Environmental Psychology, 27: 265-276.

Akama, Y. and A. Prendiville (2013) 'A phenomenological view to co-designing services’ Swedish Design Research Journal 1 (13): 29-40

Anderson, B. 2009. ‘Affective atmospheres', Emotion, Space and Society 2: 77-81.

Bille, M. 2014. 'Lighting up cosy atmospheres in Denmark', Emotion, Space and Society, http://dx.doi.org/10.1016/j.emospa.2013.12.008

Bille, M. and Sørensen, T. 2007. An anthropology of luminosity: the agency of light, Journal of Material Culture, 12(3): 263-284

Bille, M., P. Bjerregaard and T. Flohr Sørensen (2015) 'Staging atmospheres: Materiality, culture, and the texture of the in-between' Emotion, Space and Society 15: 31-38/

Bissell, D. 2010. 'Passenger mobilities: affective atmospheres and the sociality of public transport', Environment and Planning D 28: 270 -289

Böhme, G. 1993. 'Atmosphere as the fundamental concept of a new aesthetics'. Thesis Eleven 36: 113-126.

Böhme, G. 2013. The art of the stage set as a paradigm for an aesthetics of 
atmospheres, Ambiances: International Journal of Sensory Environment, Architecture and Urban Space [online] (published online 10 February 2013., http://ambiances.revues.org/315

Couldry N (2012) Media, Society, World: Social Theory and Digital Media Practice. Cambridge:

Couldry N and Markham T (2008) Troubled closeness or satisfied distance? Researching media consumption and public orientation. Media, Culture \& Society 30(1): 5-21.

Dourish, P. (2001) Where The Action Is: The Foundations Of Embodied Interaction. MIT Press, Boston.

Edensor, T. (2012) 'Illuminated atmospheres: anticipating and reproducing the flow of affective experience in Blackpool' Environment and Planning D: Society and Space, volume 30, pages $1103-1122$

Edensor, T. (2014) 'Producing atmospheres at the match: Fan cultures, commercialization and mood management in English football' Emotion, Space and Society. Available online 10 January 2014.

doi:10.1016/j.emospa.2013.12.010 
Gunn, W. and J. Donovan (2012) 'Design anthropology: an introduction’, in W. Gunn and J. Donovan (eds) Design and Anthropology. Farnham, UK: Ashgate.

Gunn, W. and J. Donovan (2012) Design and Anthropology. Farnham, UK: Ashgate.

Gunn, W., T. Otto and R. C. Smith (2013) (eds) Design Anthropology: theory and practice, Oxford: Bloomsbury Publishing.

Ingold, T. (2013) Making, Oxford: Routledge.

Harris, M. (2007) 'Introduction: ways of knowing’, in M. Harris (ed.) Ways of Knowing, new approaches in the anthropology of experience and learning. Oxford: Berghahn.

Hallam, E and T. Ingold (2007) 'Creativity and Cultural Improvisation: An Introduction’ in E. Hallam and T. Ingold Creativity and Cultural Improvisation. Oxford: Berg.

Ingold T (2000) The Perception of the Environment. London: Routledge.

Ingold T (2007) Lines: A Brief History. London: Routledge.

Ingold T (2008) Bindings against boundaries: entanglements of life in an open world.

Environment and Planning A 40: 1796-1810.

Ingold T (2011) Reply to David Howes. Social Anthropology 19(3): 323-327.

Ingold, T. 2000. The perception of the environment. London: Routledge.

Ingold, T. 2008. Bindings against boundaries: entanglements of life in an open world. Environment and Planning A 40: 1796-1810.

Ingold, T. 2011. Being Alive: essays on movement, knowledge and description, Oxford: Routledge.

Ingold, T. (2012) 'Introduction: the perception of the User-producer' in W. Gunn and J. Donovan (eds) Design and Anthropology, Farnham: Ashgate.

Leder Mackley and S. Pink (2013) ‘From emplaced knowing to interdisciplinary 
knowledge: sensory ethnography in energy research’ Senses and Society, 8(3): 335-353.

Massey D (2005) For Space. London: Sage.

Miller D. (1988) 'Appropriating the state on the council estate', Man, 23: 353-372

Miller, D. (2001) (ed) Home Possessions, Oxford: Berg.

Moores, S. (2012) Media, Place and Mobility. Basingstoke: Palgrave Macmillan.

Otto, T. and C. Smith (2013) 'Design Anthropology: a distinct style of knowing' in W. Gunn, T. Otto and R. C. Smith Design Anthropology: theory and practice, Oxford: Bloomsbury Publishing.

Pink, S. (2015) Doing Sensory Ethnography, London: Sage.

Pink, S. and K. Leder Mackley (2012) ‘Video as a Route to Sensing Invisible Energy’ Sociological Research Online, February 2012, online at http://www.socresonline.org.uk/17/1/3.html

Pink, S. and K. Leder Mackley (2014) 'Reenactment Methodologies for Everyday Life Research: Art Therapy Insights for Video Ethnography’ Visual Studies 29(2), pp.146-154

Pink, S. K. Leder Mackley, V. Mitchell, C. Escobar-Tello, M. Hanratty, T. Bhamra and R. Morosanu (2013) ‘Applying the Lens of Sensory Ethnography to Sustainable HCI' Transactions on Computer-Human Interaction 20(4). Article no. 25. http://dl.acm.org/citation.cfm?doid=2494261 
Pink, S. and K. Leder Mackley (2015, published online first 2014) 'Moving, Making and Atmosphere: routines of home as sites for mundane improvisation' Mobilities

Pink, S. and K. Leder Mackley (accepted) ‘A future-oriented visual-sensory ethnography of showering: the utility and limits of a practice approach’ Journal of Design Research

Shove, E. (2010) 'Beyond the ABC: climate change policy and theories of social change’ Environment and Planning A, 42(6): 1273-1285.

Steg, L. and C. Vlek (2009) 'Encouraging pro-environmental behavior: an integrative review and research agenda’ Journal of Environmental Psychology, 29: 309317.

Strengers, Y. (2013), Smart energy technologies in everyday life: Smart Utopia?, Consumption and Public Life, Palgrave MacMillan, London.

Weiser, M. (1996) 'Ubiquitous Computing \#1’, Computer Science Lab, Xerox Park, 1988, available online, http://www.ubiq.com/weiser/UbiHome.html, last accessed: 23.03.2015. 